\title{
Gemcitabine resistance in a highly metastatic subpopulation of a pulmonary adenocarcinoma cell line resistant to gefitinib
}

\author{
AKIRA TAKEMURA $^{1}$, AKIHIKO GEMMA ${ }^{1}$, MASAHIKO SHIBUYA ${ }^{1,2}$, KUNIKO MATSUDA $^{1}$, \\ TETSUYA OKANO ${ }^{1}$, MICHIYA NARA $^{1}$, RINTAROU NORO ${ }^{1}$, YUJI MINEGISHI ${ }^{1}$, \\ AKINOBU YOSHIMURA ${ }^{1}$ and SHOJI KUDOH ${ }^{1}$

\begin{abstract}
${ }^{1}$ Department of Internal Medicine, Division of Pulmonary Medicine, Infectious Diseases and Oncology, Nippon Medical School, 1-1-5 Sendagi, Bunkyo-ku, Tokyo 113-8602; ${ }^{2}$ Division of Respiratory Medicine, Tokyo Metropolitan Cancer and Infection Center, Komagome Hospital, 3-18-22 Honkomagome, Bunkyo-ku, Tokyo 113-8677, Japan
\end{abstract}

Received July 12, 2007; Accepted September 4, 2007

\begin{abstract}
The response rates to combination chemotherapy in metastatic non-small cell lung cancer (NSCLC) cases have been reported to be lower than those to induction chemotherapy in locally advanced cases. To understand the relationship between highly metastatic potential and chemosensitivity, we examined the drug sensitivity of a highly metastatic human lung adenocarcinoma cell subpopulation, PC9/f14, which had been previously established in an experimental metastasis model, to commonly used anti-cancer agents (paclitaxel, SN38, gemcitabine, vindesine, etoposide, cisplatin, and carboplatin) via the 3-(4, 5-dimethylthiazol-2-yl)2, 5-diphenyltetrazolium bromide assay. We found that the PC9/f14 subpopulation, which we previously reported to be resistant to gefitinib, was also resistant to gemcitabine (2',2'-difluoro-2'-deoxy-cytidine), a nucleoside analogue. To clarify the mechanisms of the gemcitabine resistance in this subpopulation, we screened the changes to the protein expression profiles of these cells after exposure to gemcitabine, using a 224-antibody microarray analysis. The exposure to gemcitabine in this subpopulation induced an increase in the expression level of the Bcl-X protein, although this expression remained unchanged in the parent cells. Apoptosis following gemcitabine exposure was depressed in the PC9/f14 subpopulation compared with parent cells, as assessed by flow cytometry and TUNEL assay. In addition, knock-down of Bcl-X by RNA interference methodology induced the recovery of gemcitabine sensitivity in PC9/f14. Phosphorylated Akt, which seems to be involved in the gefitinib resistance of this subpopulation, did not change after gemcitabine exposure. In conclusion, this highly
\end{abstract}

Correspondence to: Dr Akihiko Gemma, Department of Internal Medicine, Division of Pulmonary Medicine, Infectious Diseases and Oncology, Nippon Medical School, 1-1-5 Sendagi, Bunkyo-ku, Tokyo 113-8602, Japan

E-mail: agemma@nms.ac.jp

Key words: lung cancer, metastasis, drug resistance, gemcitabine, gefitinib, Bcl-X metastatic lung cancer subpopulation had multi-resistant characteristics, to both gemcitabine and gefitinib, which were achieved in different ways, during the process of obtaining its highly metastatic potential. The combination of anti-cancer drugs and inhibition of the molecules related with apoptosis and/or Akt pathway might be beneficial in the treatment of metastatic NSCLC.

\section{Introduction}

Lung cancer is a major cause of death in the world, both in men and women. Approximately $70 \%$ of lung cancer patients die from metastatic disease. Although chemotherapy modalities are widely used, they have failed to produce a significant improvement in prognosis. In clinical studies, many advanced cases are resistant to anti-cancer drugs. Indeed with combination chemotherapy the response rates in metastatic cases have been reported to be lower than those associated with induction chemotherapy (1-5). Therefore, it is important to analyze the relationship between a highly metastatic potential and chemosensitivity. Metastatic cells may become completely autonomous (6). Moreover, it has been suggested that decreased apoptosis may play an important role in the biological aggressiveness (7), because apoptosis is one of the main homeostatic mechanisms designed to eliminate misplaced cells and inhibit metastatic dissemination $(8,9)$.

We have previously established a highly metastatic human lung adenocarcinoma cell subpopulation, PC9/f14, in an experimental metastasis model, by the repeated inoculation of PC9 cells in nude mice and the subsequent culture of the tumour cells that were harvested from pulmonary metastatic foci. The PC9/f14 subpopulation showed a higher invasive activity in the matrigel invasion assay than the parent PC9 cells (data not shown). We have shown that this subpopulation of an adenocarcinoma cell line is naturally resistant to gefitinib, and have analyzed the cDNA expression profiles, genomic status of the EGFR gene, and the effect of gefitinib on signaling pathways in these cell lines in order to identify key mechanisms for naturally-acquired resistance to gefitinib. When compared with the parent cell lines, the gefitinib-resistant subpopulations demonstrated increased Akt phosphorylation (not inhibited 
by gefitinib), reduced PTEN protein expression, and loss of the EGFR gene mutation.

In this study, we examined the sensitivity of this subpopulation to commonly used anti-cancer agents [paclitaxel, SN38, gemcitabine, vindesine, etoposide, cisplatin (CDDP), and carboplatin] via the 3-(4, 5-dimethylthiazol-2-yl)2, 5diphenyltetrazolium bromide (MTT) assay and found that the PC9/f14 subpopulation was resistant to gemcitabine (2',2'difluoro-2'-deoxy-cytidine), a nucleoside analogue, as well as gefitinib. To clarify the mechanisms of gemcitabine resistance in this subpopulation, we screened the change to the protein expression profile of these cells after gemcitabine exposure, using a 224-antibody microarray analysis. Exposure to gemcitabine induced changes in the expression of various molecules including a remarkable increase of $\mathrm{Bcl}-\mathrm{X}$ protein in the PC9/f14 subpopulation. Analysis of the apoptotic status, and knock-down studies of Bcl-X, were also performed in this subpopulation that had shown increased levels of Bcl-X protein expression.

\section{Materials and methods}

Cell lines. The human lung adenocarcinoma cell line, PC9, and its highly metastatic subpopulation PC9/f14, were used in this study. The PC9 cell line was obtained from Tokyo Medical College, Tokyo, Japan, the PC9/f14 line was established at Nippon Medical School. Briefly, a suspension of viable tumor cells from the PC9 line $\left(5 \times 10^{5} /\right.$ mouse) was injected into the tail vein of 6-week-old nude mice. Male BALBc/c nude mice were obtained from the Charles River Co (Yokohama, Japan) and were kept in a laminar air-flow cabinet under specific pathogen-free conditions. Twelve weeks after the injection, the mice were sacrificed and their lungs were examined. When pulmonary metastatic foci were seen, they were removed from the lung and minced in Roswell Park Memorial Institute (RPMI)-1640 medium supplemented with $20 \%$ fetal calf serum (FCS). After being grown and maintained for 4 weeks, this cell line was injected into other 6-week-old mice. This entire process was performed fourteen times using SCID mice (CLEA Japan Inc, Tokyo, Japan), and resulted in the establishment of a highly metastatic cell line, designated PC9/f14 (10).

In vitro proliferation and chemosensitivity assays. Cell proliferation was measured by the MTT dye reduction method. Briefly, $2 \times 10^{4}$ cells were plated into each well of 96-well plates and exposed to particular anti-cancer drugs. After a 72-h incubation at $37^{\circ} \mathrm{C}, 20 \mu \mathrm{l}$ of the MTT stock solution $(5 \mu \mathrm{g} / \mathrm{ml})$ was added to each well, and the cells were incubated for a further $4 \mathrm{~h}$ at $37^{\circ} \mathrm{C}$. Then, the culture medium was removed, and $100 \mu 1$ of dimethyl sulfoxide was added to dissolve the dark blue crystals. Absorbances were measured with a Micro Plate Reader 3550 (Bio-Rad Japan, Tokyo, Japan) at $560 \mathrm{~nm}$ (11). The median drug concentration for $50 \%$ inhibition $\left(\mathrm{IC}_{50}\right)$ of tumor cell-growth was determined by plotting the logarithm of the anti-cancer drug concentration against the growth rate of treated cells. The sensitization factor was determined by dividing the $\mathrm{IC}_{50}$ for gemcitabine.

Antibody microarray analysis. We used the Panorama ${ }^{\mathrm{TM}} \mathrm{Ab}$ microarray cell signaling kit (Sigma, MO, USA) to analyze the protein expression profiles in the PC9 and PC9/f14 cell lines following gemcitabine exposure $(50 \mu \mathrm{g} / \mathrm{ml})$ for $24 \mathrm{~h}(12)$.

Cell extraction and immunoblotting. Whole cell extracts were prepared using the extraction buffer from the Panorama ${ }^{\mathrm{TM}}$ antibody microarray cell signaling kit (Sigma, CSAA1). Proteins were resolved by sodium dodecyl sulfate-polyacrylamide gel electrophoresis (SDS-PAGE) and electrotransferred to nitrous cellulose (NC) membranes, which were immunoprobed with the relevant antibody in phosphate-buffered saline (PBS) containing 1\% bovine serum albumin (BSA), and developed with a chemiluminescent substrate.

Antibody microarray assay. The assay was performed using the Panorama Ab microarray cell signaling kit (Sigma, CSAA1) according to the manufacturer's instructions. Briefly, $1 \mathrm{mg}$ of protein extract from treated and non-treated PC9 and PC9/f14 cells was labeled with $\mathrm{Cy} 3$. Free non-incorporated $\mathrm{Cy} 3$ dyes were separated by applying the labeled extracts on Sigma Spin post-reaction clean-up columns. An equal amount of labeled protein of both extracts $(2-10 \mu \mathrm{g} / \mathrm{ml})$ was incubated on the Panorama Ab microarray slide for 20-40 min; all washes were performed in PBS-Tween $0.05 \%$. The slides were air-dried before scanning with the GSI 4000 scanner, and images were generated with the Scan Array ${ }^{\mathrm{TM}}$ software (GSI Lumonics, Warwickshire, UK). The Quantarray ${ }^{\circledR}$ microarray analysis software was used for the analysis of the scanned Panorama antibody array slides. All the experiments were repeated at least twice.

Protein expression by Western blot analysis. PC9 and PC9/f14 cells were serum-starved and treated with a $50 \mu \mathrm{g} / \mathrm{ml}$ concentration of gemcitabine for $24 \mathrm{~h}$. Western blot analysis lysis buffer was added to the cells before sonication. The lysates were cleared by centrifugation at $14000 \mathrm{rpm}$ for $20 \mathrm{~min}$, and then $10 \mu \mathrm{l}$ of lysate containing $10 \mu \mathrm{g}$ of protein was separated by SDS-PAGE. After PAGE, the proteins were transferred to polyvinylidene difluoride (PVDF) membranes and blotted with the following primary antibodies: Bcl-X, and Caspase 7 (R\&D Systems Inc, MN, USA); C-myc, MAP1b, Calponin, CNPase, ARTS, Akt, and phosphorylated Akt (Sigma, MO, USA). The membranes were then incubated with horseradish peroxidase (HRP)-conjugated secondary antibodies (anti-rabbit IgG-HRP) and the protein was detected with electrochemiluminescenceplus (ECL-plus) (Amersham, UK) (13), a chemiluminescent signal detection system. Protein expression was traced to film-processor FPM100 film (Fuji photo Film). GAPDH protein was used as internal control. If a difference in the protein expression in the two cell lines due to gemcitabine exposure was detected by Western blot analysis, we performed quantification of protein expression in the two cell lines. This examination was performed following the same process described above for Western blot analysis until the point of primary antibody staining had been reached. However, in this secondary examination, we then used anti-rabbit IgG-Alexa Fluor 680 (Invitrogen, CA, USA) as a second antibody and anti-mouse IgG-IRDye800 (Rockland Immunochemicals Inc, PA, USA) as an internal control. Scanning and analysis was performed using an Odyssey infrared imaging system (LICOR, NE, USA). 

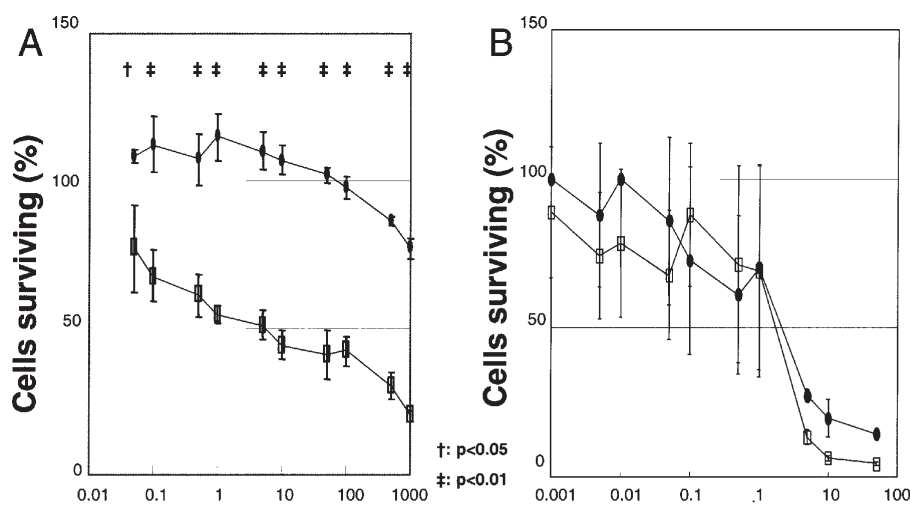

Gemcitabine concentration $(\mu \mathrm{g} / \mathrm{ml})$
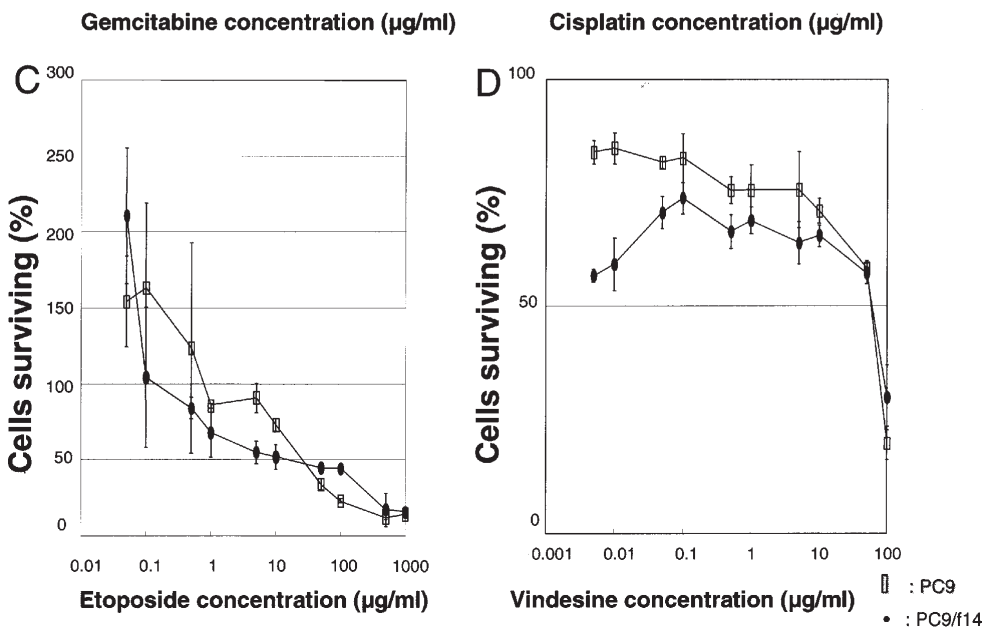

Figure 1. In vitro growth-inhibitory activity of anti-cancerous agents on PC9 and PC9/f14 lines. Using the MTT assay, we assessed the sensitivity of PC9, a human lung adenocarcinoma cell line, and PC9/f14, a highly metastatic subpopulation of PC9, to certain drugs. MTT assay analysis suggested that the PC9/f14 cell line was gemcitabine resistant (A). On the other hand, with respect to the other agents tested, there were no apparent differences between the two cell lines (B-D). Error bars represent standard deviations. Assays were performed in quadruplicate.

Measurement of apoptosis by flow cytometry. The cell population status of the 2 lines was evaluated by flow cytometry (14). Cells were trypsinized and washed twice with PBS (-), and $1 \times 10^{6}$ cells were dissolved in $1.5 \mathrm{ml}$ hypotonic fluoro-chrome solution [double staining method of annexin $\mathrm{V}$ and propidium iodine (PI), $50 \mu \mathrm{g} / \mathrm{ml}$, in $0.1 \%$ sodium citrate containing $0.1 \%$ Triton $\mathrm{X}-100]$. These samples were placed in the dark overnight, and the annexin V and PI fluorescence of individual nuclei was measured using a fluorescenceactivated cell sorting (FACS) calibur (Becton Dickinson, Mountain View, CA, USA). The data were plotted on a logarithmic scale. Percentage of apoptosis was measured by counting annexin V-positive cells (lower right and upper right fields).

TUNEL assay. Terminal deoxynucleotidyl transferase (TDB)mediated DTP nick end-labeling (TUNEL) assay was carried out using an apoptosis detection kit (Takara Bio Inc, Ohtsu, Japan) (14). Cells were cultured on sterile oversleep and treated as described. At 72-h intervals, control and treated cells were fixed in $4 \%$ paraformaldehyde in PBS, permeabilized in $0.2 \%$ Triton X-100 in PBS, and equilibrated in a buffer comprising $200 \mathrm{mM}$ potassium cacodylate, $25 \mathrm{mM}$ Tris- $\mathrm{HCl}$ ( $\mathrm{pH}$ 6.6), $0.2 \mathrm{mM}$ DTT, $2.5 \mathrm{mM} \mathrm{CoCl}_{2}$ and $0.25 \mathrm{mg} / \mathrm{ml} \mathrm{BSA}$. Labeling reactions were carried out in equilibration buffer containing $5 \mu \mathrm{M}$ fluorescein-12-dUTP, $0.1 \mathrm{mM}$ EDTA and 2.5 units of
TdT for $1 \mathrm{~h}$ at $37^{\circ} \mathrm{C}$. Reactions were terminated in $2 \mathrm{X}$ saline sodium citrate (SSC) buffer, and the cells were washed in PBS and stained in $1 \mu \mathrm{g} / \mathrm{ml}$ PI in PBS. Samples were mounted and analyzed by fluorescence microscopy.

Small interfering RNA (siRNA) transfection. Transfections were performed at approximately $50 \%$ cell confluency. Briefly, $5 \times 10^{5}$ PC9/f14 cells per dish $(10 \mathrm{~cm})$ were seeded in OPTIMEM I (Gibco 3198) without antibiotics. To prepare small interfering (si) RNA, $4 \mu \mathrm{l}$ of DharmaFECT1 (Dharmacon T2001-02) (Dharmacon Inc, Lafayette, CO, USA), which was a transfection reagent of siRNA, was mixed with $196 \mu \mathrm{l}$ of OPTI-MEM I (a). Furthermore, $2 \mu \mathrm{M}$ of siRNA solution was mixed with OPTI-MEM I $(1: 1)$ and incubated for $5 \mathrm{~min}$ at room temperature (b). $\mathrm{a}$ and $\mathrm{b}$ were then mixed and incubated for $20 \mathrm{~min}$ at room temperature. The final concentrations of the siRNA were $50 \mathrm{nM}$. siRNA and the reagent complex were added to the PC9/f14 cells in OPTI-MEM I, up to $10 \mathrm{ml} /$ dish. PC9/f14 cells were incubated for $48 \mathrm{~h}$ after transfection. We used siGENOME SMART pool BCL2L1 \#M00345800 (Dharmacon) as si Bcl-X.

\section{Results}

Effect of gemcitabine on cell growth in vitro. To determine the relationship between a highly metastatic potential and 
Table I. Protein expression profiles in PC9 and PC9/f14 lines following gemcitabine exposure, by the Panorama Ab microarray.

\begin{tabular}{|c|c|c|c|c|c|}
\hline High expressive proteins & & In PC9 & Low expressive proteins & & In PC9 \\
\hline \multicolumn{6}{|l|}{ Top 5 in PC9/f14 } \\
\hline Bcl-X & 1.22 & 0.88 & MAP1b & 0.72 & 0.83 \\
\hline Caspase 7 & 1.19 & 0.94 & SNAP-25 & 0.76 & 1.00 \\
\hline Cytokeratin 8.13 & 1.18 & 1.03 & S-100 ß & 0.78 & 0.77 \\
\hline C-myc & 1.17 & 1.02 & Phosphoserin & 0.79 & 1.01 \\
\hline PSR & 1.17 & 0.95 & RAF & 0.80 & 1.01 \\
\hline High expressive proteins & & In PC9/f14 & Low expressive proteins & & In PC9/f14 \\
\hline \multicolumn{6}{|l|}{ Top 5 in PC9 } \\
\hline Calponin & 1.44 & 0.83 & CNPase & 0.76 & 0.83 \\
\hline P38 MAPK & 1.27 & 0.94 & ARTS & 0.77 & 0.89 \\
\hline BCOP & 1.23 & 0.91 & S-100 B & 0.77 & 0.78 \\
\hline HDAC 1 & 1.22 & 0.99 & Pyk 2 phospho & 0.80 & 1.05 \\
\hline JNK & 1.20 & 1.04 & APP & 0.80 & 0.90 \\
\hline
\end{tabular}

Protein expression ratio compared with gemcitabine non-treated cell line.
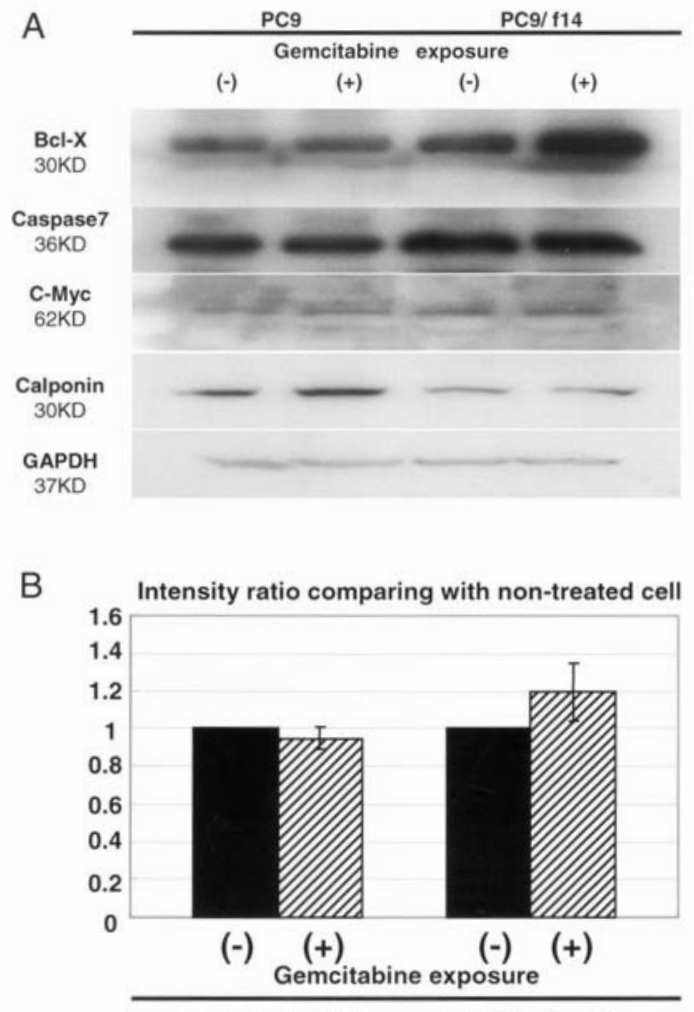

Figure 2. Protein expression by Western blot analysis. Bcl-X protein expression was up-regulated after exposure of the PC9/f14 cell line to gemcitabine, but there was no difference after exposure of the PC9 cell line (Western blot analysis) (A). Caspase7, C-myc, and Calponin protein expression was not up-regulated in either the PC9 or the PC9/f14 cell lines after exposure to gemcitabine (Western blot analysis). Quantification of Bcl-X expression after gemcitabine exposure by Western blot analysis, suggested that Bcl-X protein was overexpressed by approximately 1.2 times after exposure of the PC9/f14 cell line to gemcitabine (B). Error bars represent standard deviations. Experiments were performed in triplicate. chemosensitivity, anti-cancer drug sensitivity tests using MTT analysis were performed on the PC9 cell line and PC9/f14, a highly metastatic subpopulation. Anti-cancer drugs commonly used for lung cancer chemotherapy, namely, CDDP, etoposide, vindesine, gemcitabine, paclitaxel, SN38, and carboplatin, were selected for our analyses (Fig. 1A-D). PC9/f14 with a highly metastatic potential, which we have previously reported to be resistant to gefitinib, was also shown to be resistant to gemcitabine (13).

Gemcitabine exposure induced changes in protein expression in PC9 and/or PC9/f14. To identify the changes in protein expression after gemcitabine exposure, antibody microarray analysis was performed. In over 224 proteins examined, the expression levels of several molecules varied during gemcitabine exposure in PC9 and/or PC9/f14 (Table I): Bcl-x protein was up-regulated and MAP1b was down-regulated in PC9/f14 after gemcitabine exposure at the highest level (Table I). In the case of PC9, Calponin was up-regulated and CNPase was down-regulated at the highest level. The molecules with distinct differences between PC9 and PC9/f14, in the change of protein expression level after gemcitabine exposure, were Bcl-X and Calponin.

We compared the expression levels of $\mathrm{Bcl}-\mathrm{X}$ before and after gemcitabine exposure both in PC9 and PC9/f14 using Western blot analysis. In PC9/f14, the Bcl-X band significantly increased while in the PC9 cell line it was stable (Fig. 2A and B). Among the other proteins which ranked in the list of the top 5, the most frequently changed ones in PC9/f14, such as Caspase 7 and C-myc, no such apparent difference was observed (Fig. 2A and B). Calponin was also stable in PC9/ f14.

In addition, phosphorylated Akt, which seemed to be related to gefitinib resistance in this subpopulation, was stable 


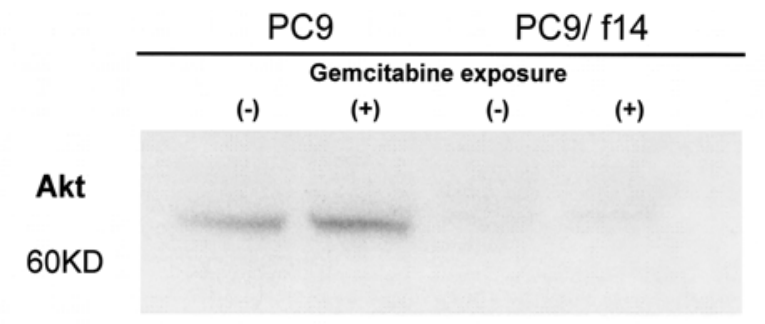

pAkt

60KD

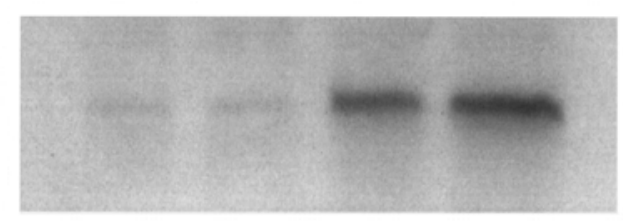

\section{GAPDH}

$37 \mathrm{KD}$

Figure 3. Akt and pAkt protein expression by Western blot analysis. The expression levels of Akt and phosphorylated Akt proteins were detected by Western blot analysis. These examinations concluded that the expression of Akt and phosphorylated Akt proteins remained unaffected following gemcitabine exposure.

during gemcitabine exposure (Fig. 3). These results suggested that in the $\mathrm{PC} / \mathrm{f} 14$ cell line, while an increase of Bcl-X protein seemed to be related to gemcitabine resistance, phosphorylated Akt was not.

Analyzed apoptosis. Because Bcl-X is a well-known apoptosisrelated protein, the apoptotic status of PC9 and PC9/f14 was evaluated after gemcitabine exposure. After $72 \mathrm{~h}$ of gemcitabine $(50 \mu \mathrm{g} / \mathrm{ml})$ exposure, the cell populations were analyzed using flow cytometry. Apoptotic cell population in the PC9 cell line accounted for $41.24 \%$ of cells, while the corresponding value in the PC9/f14 cell line was $10.16 \%$ (Fig. 4). In addition, a TUNEL assay was performed for the evaluation of DNA fragmentation in both PC9 and PC9/f14 cells. Intense nuclear staining was observed more frequently in the gemcitabine-treated PC9 cell line than in PC9/f14 (Fig. 5). These results indicated that apoptosis following gemcitabine exposure was suppressed in the PC9/f14 subpopulation compared with parent cells.

Effect of gemcitabine on PC9/f14 cell line after transfection of $B c l$-X specific small interfering RNA (siRNA). We performed the transfection of Bcl-X specific siRNA and non-specific control, on the PC9/f14 cell line, and examined gemcitabine sensitivity using the MTT assay. Compared with the control PC9/f14 cell line, the Bcl-X down-regulated PC9/f14 cell line was sensitive to gemcitabine (Fig. 6). This result suggested that $\mathrm{Bcl}-\mathrm{X}$ was associated with gemcitabine-resistant mechanisms in the PC9/f14 cell line.

\section{Discussion}

A number of combination therapy regimens have proven to be effective and are widely applied to the treatment for metastatic
A

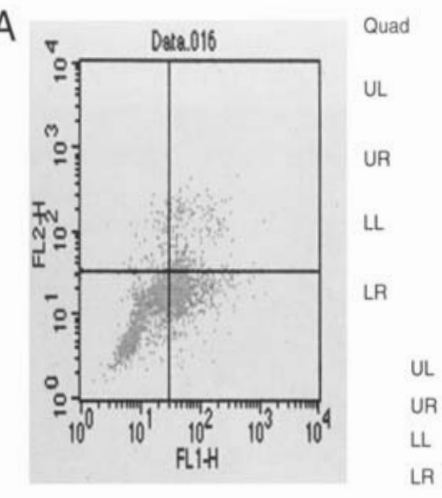

\%Total

82

2.89

0.82

295

10.38

2.95

1588

55.88

15.88

877

30.86

8.77

: upper left

upper right

lower left

: lower right

B

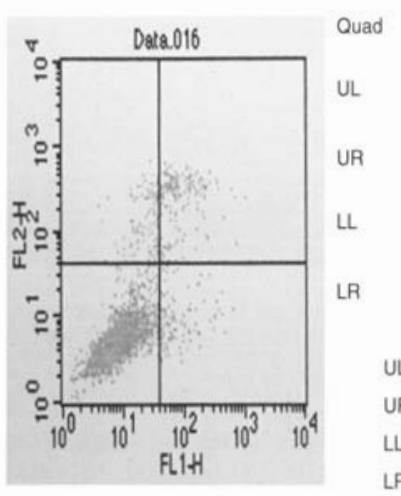

Events
117
207
2649
106
: upper left
: upper right
: lower left
: lower right

\%Gated \%Total

$\begin{array}{ll}3.8 & 1.17\end{array}$

$6.72 \quad 2.07$

$86.03 \quad 26.49$

3.44

1.06

Figure 4. Apoptosis after gemcitabine exposure in PC9 and PC9/f14 cell lines by flow cytometry analysis. After exposure to gemcitabine, flow cytometry detected that apoptotic cell population of the PC9 cell line was $41.2 \%$ (A). On the other hand in the PC9/f14 cell line, apoptotic cell population was $10.2 \%$ (B). These results suggested that the PC9/f14 cell line was an anti-apoptotic cell line with respect to response to gemcitabine exposure.

NSCLC. The effect of these therapies on improving patient survival remains far from satisfactory. It is consequently desirable to find more appropriate therapeutic opportunities based on informed insights. In our previous and present studies, a highly metastatic subpopulation of lung adenocarcinoma, PC9/f14, has shown simultaneous, multi-drug resistance to gefitinib and gemcitabine $(10,13)$. The development of this multi-drug resistance seems to be accompanied with highly metastatic potential. The analysis of its mechanisms seems to be useful for our understanding of the relationship between highly metastatic potential and chemosensitivity.

Gemcitabine is structurally related to deoxycytidine, with fluorine substitutes for the two hydrogen atoms in the $2^{\prime}$ position of the deoxyribose sugar, and has been shown to be one of the most active chemotherapeutic agents in several solid tumors, especially in NSCLC (15). Gemcitabine enters the cell via a nucleoside transport system (16), and is activated to its difluorodeoxycytidine triphosphate, which is incorporated into DNA or RNA, consequently leading to chain termination. However, the molecular pathway(s) by which this drug causes cell death have not yet been fully defined. Pathways concerned with several proteins, such as Bcl-2, P53, Fas, Bcl-X, NF-кB, Caspase, Integrin-linked-kinase, ERK, and Akt, are all considered to be related to gemcitabine sensitivity or resistance 


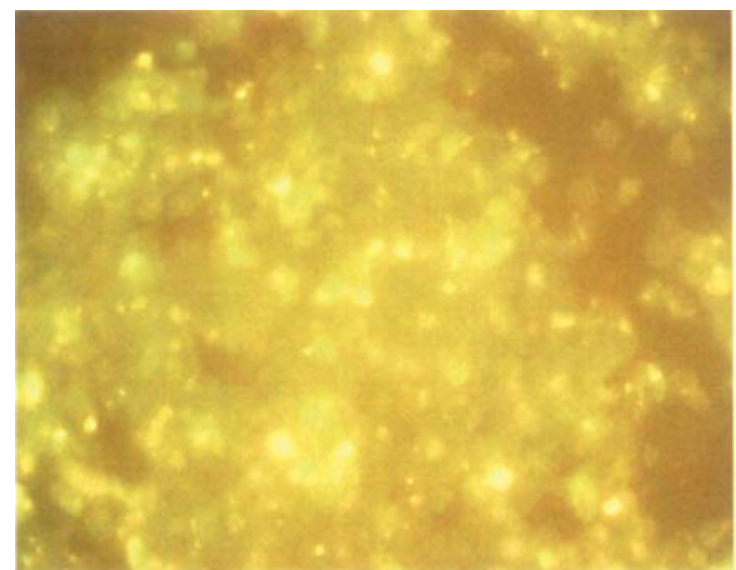

Apoptosis in PC9 cell line

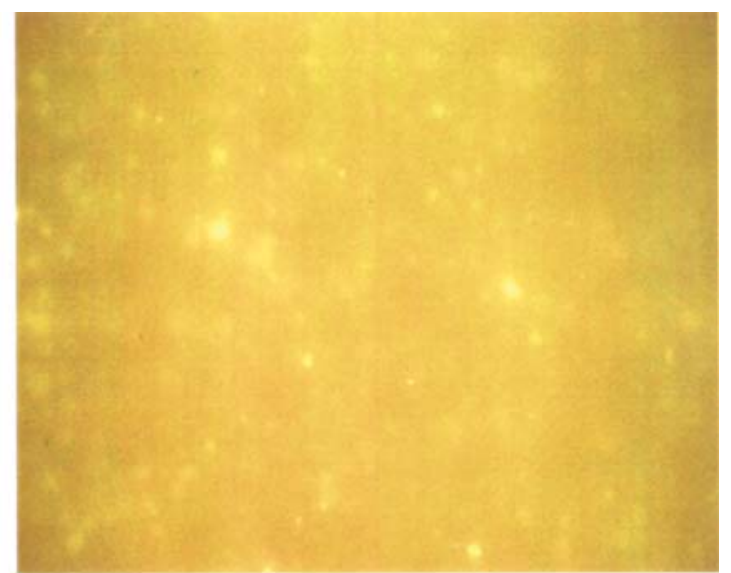

Apoptosis in PC9/f14 cell line

Figure 5. Apoptosis after gemcitabine exposure in PC9 and PC9/f14 cell lines by TUNEL assay. TUNEL staining was performed on PC9 and PC9/f14 cell lines, which were grown on sterile coverslips, treated with gemcitabine, and end-labeled at 72-h intervals with fluorescein-conjugated 12-dUTP, and then examined by fluorescence microscopy. The results of this analysis supported those of the flow cytometry analysis which found that the PC9/f14 cell line was an anti-apoptotic cell line with respect to its response to gemcitabine exposure.

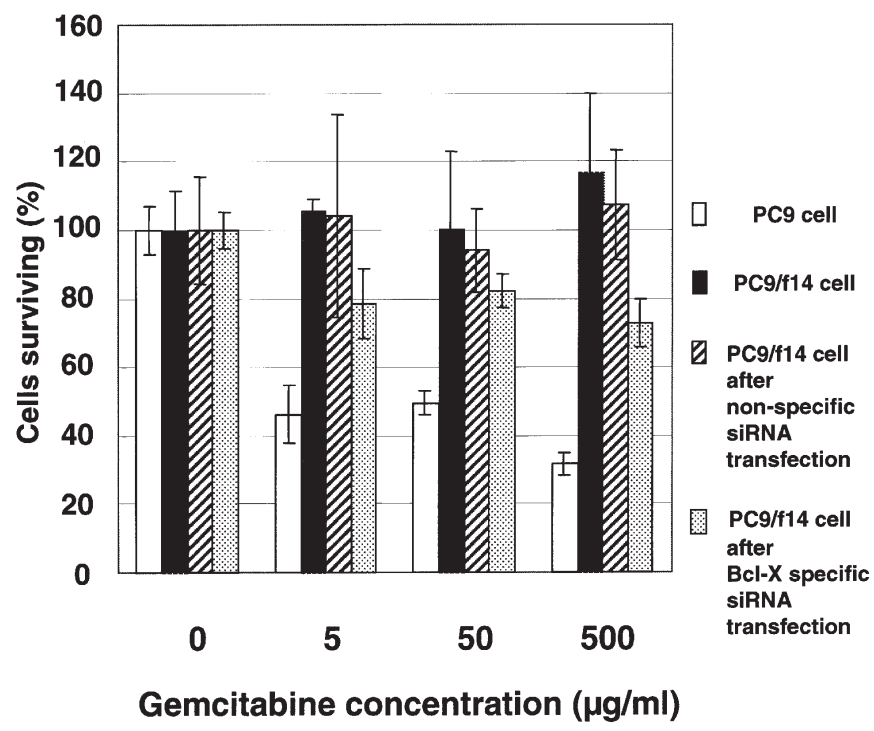

Figure 6. Effect of gemcitabine on the PC9/f14 line after transfection with Bcl-X specific siRNA. We performed the transfection of Bcl-X specific siRNA on the PC9/f14 cell line, and examined gemcitabine sensitivity by MTT assay. This result suggested that Bcl-X appears to be associated with the gemcitabineresistant mechanism on the PC9/f14 cell line.

(17-25). In this study, the exposure to gemcitabine in this subpopulation with gemcitabine resistance induced an increase in the expression level of the Bcl-X protein, although this expression remained unchanged in the parent cells. Knockdown of Bcl-X by RNA interference induced the recovery of gemcitabine sensitivity in PC9/f14. Human Bcl-X comprises two distinct spliced mRNAs, designated $\mathrm{Bcl}-\mathrm{X}_{\mathrm{L}}$ and $\mathrm{Bcl}-\mathrm{X}_{\mathrm{S}}$. The predicted protein product of the longer transcript, $\mathrm{Bcl}-\mathrm{X}_{\mathrm{L}}$, shows remarkable homology to Bcl-2 and, like Bcl-2, seems to inhibit apoptosis in some cells. Increased $\mathrm{Bcl}-\mathrm{X}_{\mathrm{L}}$ expression has been observed in several malignancies, including gastric
(26), colorectal (27), ovarian (28), and prostate (29) carcinomas, amongst others $(30,31)$. It has been reported that $\mathrm{Bcl}-\mathrm{X}_{\mathrm{L}}$ antisense oligonucleotide treatment increases the sensitivity of pancreatic cancer cells to gemcitabine (21). Another study suggested that the down-regulation of $\mathrm{Bcl}-2$ and $\mathrm{Bcl}-\mathrm{X}_{\mathrm{L}}$ increased the levels of cytosolic cytochrome c, and activation of Caspase-9, in gemcitabine-treated cells. Overexpression of Bcl-2 protein, by adeno-Bcl-2 viral vector infection, markedly blocked gemcitabine-mediated apoptotic cell death in some cells, suggesting that $\mathrm{Bcl}-2$ family-dependent mitochondrial pathway plays a role in mediating gemcitabine-induced apoptosis (25). Furthermore, Bcl- $\mathrm{X}_{\mathrm{L}}$ also blocks the activation of the intrinsic apoptotic pathway in the response of cells to genotoxic stress (32). These present and previous results suggest that $\mathrm{Bcl}-\mathrm{X}_{\mathrm{L}}$ is related to gemcitabine resistance, and that $\mathrm{Bcl}-\mathrm{X}$ can be considered as a drug resistance-related protein inducing anti-apoptotic mechanisms.

We used a 224-antibody array for the identification of the factors related to the resistance. Although protein profiling is technologically easier for the identification of the factors than transcript profiling, the number of evaluated factors is smaller. Additional mechanisms might be identified using other profiling methodology. Knock-down of Bcl-X by RNA interference methodology induced the recovery of gemcitabine sensitivity in PC9/f14. However, the recovery of sensitivity in this subpopulation seemed to be partial. There is a possibility that other additional mechanisms might be related to the gemcitabine resistance in this subpopulation.

We previously reported that the PC9/f14 cell line was resistant to gefitinib and that the loss of the PTEN protein, enhanced by overactivation of phosphorylated Akt protein, was the cause of this resistance (13). However in the current study, the phosphorylated state of Akt protein was stable during gemcitabine exposure in both PC9 and PC9/f14. PTEN and phosphorylated Akt proteins might not act as apoptosis-related proteins on gemcitabine exposure. On the other hand, Bcl-X 
increased after gemcitabine exposure only in PC9/f14. Taken together, these results indicated that this highly metastatic subpopulation is possibly multi-drug resistant through at least two different mechanisms; increased Bcl-X and phosphorylated Akt.

In conclusion, clinically-advanced cases seem to be resistant to anti-cancer drugs. The mechanisms of anti-cancer drug resistance shown in this study might relate to metastatic potential. The highly metastatic PC9/f14 cell line is multidrug resistant. Gemcitabine resistance might be related with the overexpression of Bcl-X protein, without phosphorylated Akt protein, which is concerned with gefitinib resistance. During the metastatic process, the mechanisms involved in these alterations in expression might occur simultaneously. In an experimental metastasis model based on the repeated inoculation of PC9 cells into nude mice, and the subsequent culture of the tumour cells from pulmonary metastatic foci, anti-apoptotic mechanism and phosphorylated state of Akt might both be required. The combination of anti-cancer drugs and inhibition of the molecules concerned with apoptosis (using RNA interference etc.) and/or Akt pathway might prove to be a beneficial treatment strategy in advanced lung cancer.

\section{Acknowledgements}

Supported in part by a Grant-in-Aid from the Ministry of Education, Culture, Sports, Science, and Technology of Japan and Japan Society for the Promotion of Science.

\section{References}

1. Burkes RL, Shepherd FA, Blackstein ME, Goldberg ME, Waters PF, Patterson GA, Todd T, Pearson FG, Jones D, Farooq S, McGlaughlin J and Ginsberg RJ: Induction chemotherapy with mitomysin, vindesine, and cisplatin for stage IIIA (T1-3, N2) unresectable non-small-cell lung cancer: final results of the Toronto phase II trial. Lung Cancer 47: 103-109, 2005.

2. Socinski MA, Rivera MP and Detterbeck FC: Gemcitabinebased combinations as preoperative therapy in resectable nonsmall-cell lung cancer. Clin Lung Cancer 4 (suppl 2): S50-S55, 2003.

3. Cigolari S, Curcio C, Maiorino A, Sessa R, Cioffi A and Massimo M: Cisplatin plus vinorelbine as induction chemotherapy followed by surgery in the treatment of stage IIIB non-small cell lung cancer. Final results of a multi-center phase II study. Anticancer Res 23: 1803-1809, 2003.

4. Ohe Y, Ohashi Y, Kubota K, Tamura T, Nakagawa K, Nagoro S, Nishiwaki Y, Saijo N, Ariyoshi Y and Fukuoka M: Randomized phase III study of cisplatin plus irinotecan versus carboplatin plus paclitaxel, cisplatin plus gemcitabine, and cisplatin plus vinorelbine for advanced non-small-cell lung cancer; Four-Arm Cooperative Study in Japan. Ann Oncol 18: 317-323, 2007.

5. Cobo DM, Villar CE, Ales DI, Gil CS, Alcalde GJ, Gutierrez CV, Carabantes OF, Montesa PA, Breton GJJ and Benavides OM: Gemcitabine and vinorelbine followed by weekly docetaxel in patients with advanced non-small-cell lung cancer: a phase II trial of sequential chemotherapy. Clin Transl Oncol 8: 742-749, 2006.

6. Nicolson GL: Paracrine and autocrine growth mechanisms in tumor metastasis to specific sites with particular emphasis on brain and lung metastasis. Cancer Metastasis Rev 12: 325-343, 1993.

7. Wu J: Apoptosis and angiogenesis: two promising tumor markers in breast cancer (review). Anticancer Res 16: 2233-2239, 1996.

8. Glinsky GV, Glinsky VV, Ivanova AB and Hueser CJ: Apoptosis and metastasis: increased apoptosis resistance of metastatic cancer cells is associated with the profound deficiency of apoptosis execution mechanisms. Cancer Lett 115: 185-193, 1997.
9. Jaattela M: Escaping cell death: survival proteins in cancer. Exp Cell Res 248: 30-43, 1999.

10. Gemma A, Takenaka K, Hosoya Y, Matuda K, Seike M, Kurimoto F, Ono Y, Uematsu K, Takeda Y, Hibino S, Yoshimura A, Shibuya M and Kudoh S: Altered expression of several genes in highly metastatic subpopulations of a human pulmonary adenocarcinoma cell line. Eur J Cancer 37: 1554-1561, 2001.

11. Shinoda K, Shibuya M, Hibino S, Ono Y, Matsuda K, Takemura A, Zou D, Kokubo Y, Takechi A and Kudoh S: A novel matrix metalloproteinase inhibitor, FYK-1388 suppresses tumor growth, metastasis and angiogenesis by human fibrosarcoma cell line. Int J Oncol 22: 281-288, 2003.

12. Kopf E, Shnitzer D and Zharhary D: Panorama Ab Microarray Cell Signaling Kit: a unique tool for protein expression analysis. Proteomics 5: 2412-2416, 2005.

13. Kokubo Y, Gemma A, Noro R, Seike M, Kataoka K, Matsuda K, Okano T, Minegishi Y, Yoshimura A, Shibuya M and Kudoh S: Reduction of PTEN protein and loss of epidermal growth factor receptor gene mutation in lung cancer with natural resistance to gefitinib (IRESSA). Br J Cancer 92: 1711-1719, 2005.

14. Patel V, Ensley JF, Gutkind JS and Yeudall WA: Induction of apoptosis in head-and-neck squamous carcinoma cell by gammairradiation and bleomycin is p53-independent. Int J Cancer 88: 737-743, 2000

15. Bunn PAJ and Kelly K: New chemotherapeutic agents prolonged survival and improve quality of life in non-small cell lung cancer: a review of the literature and future directions. Clin Cancer Res 4: 1087-1100, 1998

16. Graham KA, Leithoff J, Coe IR, Mowles D, Mackey JR, Young JD and Cass CE: Differential transport of cytosinecontaining nucleosides by recombinant human concentrative nucleoside transporter protein hCNT1. Nucleosides Nucleotides Nucleic Acids 19: 415-434, 2000.

17. Merimsky O, Hirsh L, Dantes A, Land BA, Suh BS and Amsterdam A: Induction of apoptosis in non-small lung carcinoma cell line (H1299) by combination of anti-asthma drugs with gemcitabine and cisplatin. Int J Oncol 26: 475-482, 2005.

18. Galmarini CM, Clarke ML, Falette N, Puisieux A, Mackey JR and Dumontet C: Expression of a non-functional P53 affect the sensitivity of cancer cell to gemcitabine. Int J Cancer 97: 439-445, 2002.

19. Meli M, Tolomeo M, D'Alessandro N, Grimaudo S, Notarbartolo M, Papoff G, Ruberti G, Rausa L and Dusonchet L: Resistance to gemcitabine in a lymphoma cell line resistant to Fas-mediated apoptosis. Anticancer Res 24: 851-857, 2004.

20. Alvero AB, O'Malley D, Brown D, Kelly G, Garg M, Chen W, Rutherford T and Mor G: Molecular mechanism of phenoxodiolinduced apoptosis in ovarian carcinoma cells. Cancer 106 599-608, 2006.

21. Xu Z, Friess H, Solioz M, Aebi S, Korc M, Kleeff J and Buchler MW: Bcl-x(L) antisense oligonucleotides induce apoptosis and increase sensitivity of pancreatic cancer cells to gemcitabine. Int J Cancer 94: 268-274, 2001.

22. Yokoi $\mathrm{K}$ and Fidler IJ: Hypoxia increases resistance of human pancreatic cancer cells to apoptosis induced by gemcitabine. Clin Cancer Res 10: 2299-2306, 2004.

23. Chandler NM, Canete JJ and Callery MP: Caspase-3 drives apoptosis in pancreatic cancer cells after treatment with gemcitabine. J Gastrointest Surg 8: 1072-1078, 2004

24. Yau CY, Wheeler JJ, Sutton KL and Hedley DW: Inhibition of integrin-linked kinase by a selective small molecule inhibitor, QLT0254, inhibits the PI3K/PKB/mTOR, Stat3, and FKHR pathways and tumor growth, and enhances gemcitabine-induced apoptosis in human orthotopic primary pancreatic cancer xenografts. Cancer Res 65: 1497-1504, 2005.

25. Chang GC, Hsu SL, Tsai JR, Wu WJ, Chen CY and Sheu GT: Extracellular signal-regulated kinase activation and Bcl-2 downregulation mediated apoptosis after gemcitabine treatment partly via a p53-independent pathway. Eur J Pharmacol 502: 169-183, 2004.

26. Kondo S, Shinomura Y, Kanayama S, Higashimoto Y, Miyagawa JI, Minami T, Kiyohara T, Zushi S, Kitamura S, Isozaki $\mathrm{K}$ and Matsuzawa $\mathrm{Y}$ : Over-expression of bcl- $\mathrm{x}_{\mathrm{L}}$ gene in human gastric adenomas and carcinomas. Int J Cancer 68: 727-730, 1996.

27. Krajewska M, Moss SF, Krajewski S, Song K, Holt PR and Reed JC: Elevated expression of bcl-x and reduced Bak in primary colorectal adenocarcinomas. Cancer Res 56: 2422-2427, 1996. 
28. Liu JR, Fletcher B, Page C, Hu C, Nunez G and Baker V: Bcl- $x_{L}$ is expressed in ovarian carcinoma and modulates chemotherapyinduced apoptosis. Gynecol Oncol 70: 398-403, 1998.

29. Liu QY and Stein CA: Taxol and estramustine-induced modulation of human prostate cancer cell apoptosis via alteration in bcl- $\mathrm{x}_{\mathrm{L}}$ and bak expression. Clin Cancer Res 3: 2039-2046, 1997.

30. Dole MG, Jasty R, Cooper MJ, Thompson CB, Nunez G and Castle VP: Bcl- $\mathrm{x}_{\mathrm{L}}$ is expressed in neuroblastoma cells and modulates chemotherapy-induced apoptosis. Cancer Res 55: 2576-2582, 1995.
31. Foreman KE, Wrone ST, Boise L, Thompson CB, Polverini PJ, Simonian PL, Nunez G and Nickoloff BJ: Kaposi's sarcoma tumor cells preferentially express Bcl- $\mathrm{x}_{\mathrm{L}}$. Am J Pathol 149: 795-803, 1996.

32. Raina D, Khardanda S and Kufe D: The MUC1 oncoprotein activates the anti-apoptotic phosphoinositide 3-kinase/Akt and BCL- $\mathrm{X}_{\mathrm{L}}$ pathways in Rat 3 Y1 Fibroblasts. J Biol Chem 279: 20607-20612, 2004. 